\title{
Fuzzy linguistic hedges for the selection of manufacturing process for prosthetic sockets
}

\author{
Richa Pandey ${ }^{a}$, L. N. Pattanaik ${ }^{b^{*}}$ and S. Kumar \\ ${ }^{a}$ Department of Mechanical Engineering, Birla Institute of Technology, Mesra, Ranchi, India \\ ${ }^{b}$ Department of Production Engineering, Birla Institute of Technology, Mesra, Ranchi, India \\ ${ }^{c}$ Department of Mechanical Engineering, GLA University, Mathura, India \\ C H R O N I C L E \\ A B S T R A C T
}

Article history:

Received February 14, 2014

Accepted May 29, 2014

Available online

June 202014

Keywords:

Linguistic Hedges

Fuzzy Logic

Analytical Hierarchy Process

Reverse Engineering

Prosthetic Sockets

\begin{abstract}
In this paper, a comparison is presented between two prime methods of producing prosthetic sockets by using the fuzzy linguistic hedges approach on the qualitative feedback of Indian prosthetic users. Recent trends indicate that the Indian manufacturers have tried to adopt the newer technologies like reverse engineering (RE) approach to achieve the desired goals. However, the satisfaction of the user is of utmost importance for the unique and customized products for rehabilitation. In order to analyze the effectiveness of the manufacturing approaches, user case studies are taken, based on the linguistic feedbacks, and a comparative study is conducted. Thirteen users from four different manufacturing units are taken for study and sockets made by conventional as well as RE are experimented. Fuzzy membership functions are constructed using the linguistic hedges based on the user feedbacks. An analytical hierarchy process (AHP) is applied to arrive at a decision to select the manufacturing process for user satisfaction and manufacturing excellence.
\end{abstract}

(c) 2014 Growing Science Ltd. All rights reserved.

\section{Introduction}

The aim of custom fit prosthetics is to improve the quality of life of the user by providing optimized individual geometrical shape and requirements. In this context, the selection of the best fit method of fabrication of the prosthetic socket from the conventional method and the CAD/CAM/RE methodology is discussed in the present work. From the feedback of the prosthetic users and manufactures in qualitative linguistic terms and through a fuzzy QFD (quality function deployment) approach, the ranking of the parameters to reach the desired goal has been selected. On the basis of the weights of the needs, the ranking has shown that the most important feature for the prosthetic sockets is the manufacturing process followed by cost, material, smart technology, accuracy and surface finish. The objective of this paper is to apply a fuzzy multi-criterion approach for selection of fabrication technique using AHP based on user provided linguistic hedges. A fuzzy set is a class of objects with a continuum of grades of membership. Such a set is characterized by a membership function which assigns to each object a grade of membership ranging between zero and one (Zadeh,

* Corresponding author.

E-mail address: lnpattanaik@bitmesra.ac.in (L. N. Pattanaik)

(C) 2014 Growing Science Ltd. All rights reserved doi: $10.5267 /$ j.ds1.2014.6.002 
1965). A substantive departure from the conventional fuzzy techniques of system analysis was proposed by using linguistic variables in place of numerical values (Zadeh, 1972). A linguistic variable is defined as a variable whose values are sentences in a natural or artificial language. Thus if tall, not tall, very tall, very very tall, etc. are values of height, then height is a linguistic variable. Similarly a linguistic hedge such as very, more or less, much, essentially, slightly, etc. may be viewed as an operator which acts on the fuzzy set representing the meaning of its operand. For example, in the case of the composite term very tall man, the operator very acts on the fuzzy meaning of the term tall man (Zadeh, 1972). Detailed works on linguistic variable and its applications to approximate reasoning are found in three published papers by Zadeh (1975). Further discussions on extended hedge algebras and their applications to fuzzy logic can be found in Nguyen and Wechler (1992), Lascio et al (1996) and Nguyen and Huynh (2002).

Some pioneering works on CAD/CAM applications to prosthetics can be found in Foort et al (1985), Klasson (1985) and Holden and Fernie (1986). Continuing this trend some recent applications can be found in Nepal et al (2011) where a case study in a North American orthopaedic industry was cited. Dangayach and Deshmukh (2005) presented a survey based analysis on status, scope and implementation criteria of advanced manufacturing technologies in 122 Indian firms from SME sector. A fuzzy AHP approach for the determination of importance of weights of customer requirements in QFD can prove to be quite beneficial. The data which is vague and unclear with consistent needs to be compared pair wise using a AHP technique. This approach was used to improve the imprecise rating of the customer requirements (Kwong and Bai, 2002). Ozden Bayazit (2005) presented an application of AHP tool in flexible manufacturing systems and Aktepe \& Ersoz (2011) applied the fuzzy AHP to an industrial case study for the supplier selection process. The priority weights were calculated using the extent analysis method and the integral value calculation. Similarly Lee et al (2011) published a fuzzy AHP application for the selections in a green supply chain for a case study in Taiwan and Daim et al (2012) applied AHP for the selection of 3PL providers.

In section 2, the methodology for forming fuzzy linguistic hedges is presented. Application of the fuzzy linguistic hierarchy approach to various manufacturing case studies and the results are analyzed in $\S 3$. The concluding remarks on the work is presented in $\S 4$.

\section{Formation of Fuzzy Linguistic Hedges}

Four manufacturing units dealing with fabrication of prosthetic sockets have been surveyed for the purpose of comparing between $\mathrm{CAD} / \mathrm{CAM}$ with conventional or manual method. The manufacturing excellence and user satisfaction are related to a number of factors or features which may be technical, design and process-based. The following parameters have been ranked or prioritized using a QFD (quality function deployment) tool on the feedbacks obtained from several manufacturers and users:

- Manufacturing process $(C 1)$

- Material $(C 2)$

- Smart Technology $(C 3)$

- Cost Effectiveness $(C 4)$

- Serviceability (C5)

In a fuzzy logic based system, sometimes the information is described linguistically. The linguistic hedge is an operator like a modifier used to modify the shape of membership functions. Linguistic hedge operators can be classified into three categories: concentration, dilation and contrast intensification. In this paper, only the concentrator and the dilators are used. 


\subsection{Concentrators and dilators}

Applying a concentration operator to a fuzzy set results in the reduction of magnitude to the grade of membership. In contrast, the effect of dilation is opposite to that of concentration. The reinforcing modifiers provide a characterization which is stronger than the original one. Zadeh (1972) proposed the modifier very associated with the transformation $\operatorname{tm}(\mu)=\mu^{2}$. More generally one can think of modifiers defined by transformations such that $\operatorname{tm}(\mu) \leq \mu$, for any $\mu \in[0,1]$. Other examples of these quantifiers include extremely, positively etc. Linguistic hedges with mathematical expressions proposed by Zadeh and others are shown in Table 1.

Table 1

Definitions of linguistic hedges

\begin{tabular}{cccc}
\hline \multicolumn{2}{c}{ Concentrators } & & Dilators \\
\hline Hedge & Operator definition & Hedge & Operator definition \\
\hline Very F & F squared & More or less & Square root of F \\
Very Important F & F to power 1.5 & Less Important & F to power 0.75 \\
Extremely F & F to power 1.25 & Minus F & F to power 0.3 \\
Plus F & F to power 0.8 & Insignificant & F to power 0.2 \\
Very Very F & F to power 0.4 & & \\
\hline
\end{tabular}

The weakening modifiers provide a new characterization that is less strong than the original one. Zadeh introduced the modifier more or less, associated with the transformations $\operatorname{tm}(\mu)=\mu^{1 / 2}$. Other weakening modifiers can be defined by choosing a transformation $\operatorname{tm}(\mu) \geq \mu$ for any $\mu \in[0,1]$. Other examples of these quantifiers include more or less, negatively etc.

\subsection{Development of membership Functions}

There are several methods to get reasonable membership functions. Here is an illustration of one such method. Suppose one needs to model the notion of high performance with a fuzzy set as shown in Fig. 1, then the set $U$ with a positive real numbers representing the totality of possible performance of the manufacturing units (as judged by the users).

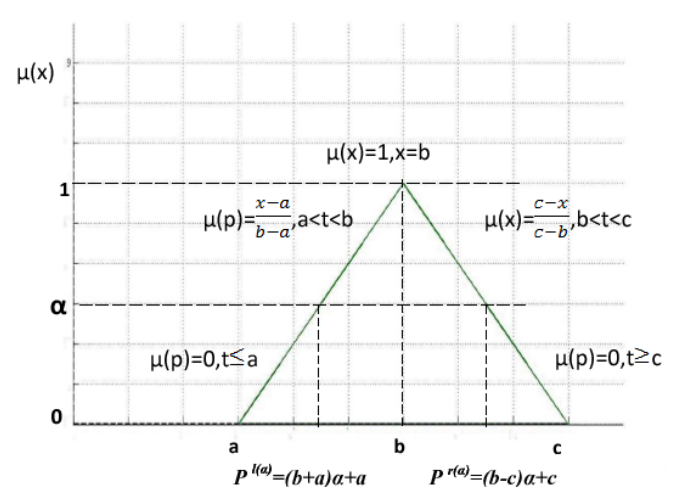

Fig. 1. Membership function development for fuzzy linguistic hedges

Then by surveying a large number of users and finding out about the performance of the manufacturing process in a particular range, the proportion $p$ of customers who thought that the performance $(t)$ of manufacturing unit lies between (5 and 20) is high, is approximately equal to $p=$ $(t-5) /(20-5)$. Of course everyone thought that the performance over 20 is high. The model of the fuzzy set "high performance" would be 
$\mu_{p}=\left\{\begin{array}{lr}(t-5) / 15, & 5 \leq t \leq 20 \\ 1, & 20 \leq t\end{array}\right.$

Similarly, for other criteria fuzzy sets are modelled.

\section{Application to case studies}

Taking into account the two main types of manufacturing process for the prosthetic sockets, the data from the four users are collected separately for each product type. Table 2 presents the compiled linguistic data from the users for the various sub-criteria of manufacturing process.

Table 2

Linguistic data for different parameters of Manufacturing Process- MP (C1)

\begin{tabular}{|c|c|c|c|c|c|c|c|c|c|c|}
\hline & $\begin{array}{l}\text { User } \\
\text { No. }\end{array}$ & $\begin{array}{c}\text { Shape } \\
\text { Matching }\end{array}$ & $\begin{array}{c}\text { Shape } \\
\text { Retrieval }\end{array}$ & $\begin{array}{c}\text { Shape } \\
\text { management }\end{array}$ & $\begin{array}{l}\text { Biomechanical } \\
\text { Shape standard }\end{array}$ & $\begin{array}{c}\text { Shape } \\
\text { Sensing }\end{array}$ & $\begin{array}{l}\text { Graphic } \\
\text { Analysis }\end{array}$ & $\begin{array}{c}\text { time } \\
\text { elapsed }\end{array}$ & Custom Fit & $\begin{array}{c}\text { Further } \\
\text { Processing }\end{array}$ \\
\hline \multirow{4}{*}{ Manual } & $1(\mathrm{M})$ & 2 & 1 & 1 & 1 & 1 & 1 & 1 & 2 & 2 \\
\hline & $2(\mathrm{M})$ & 1 & 1 & 2 & 1 & 2 & 1 & 2 & 1 & 1 \\
\hline & $3(\mathrm{~F})$ & 2 & 2 & 2 & 3 & 3 & 1 & 2 & 3 & 2 \\
\hline & $4(\mathrm{M})$ & 2 & 2 & 3 & 2 & 1 & 1 & 1 & 3 & 1 \\
\hline \multirow{6}{*}{ RE-based } & Total & 7 & 6 & 8 & 7 & 7 & 4 & 6 & 9 & 6 \\
\hline & $1(\mathrm{M})$ & 5 & 5 & 3 & 4 & 4 & 4 & 3 & 3 & 5 \\
\hline & $2(\mathrm{M})$ & 4 & 4 & 4 & 5 & 5 & 4 & 3 & 4 & 4 \\
\hline & $3(\mathrm{~F})$ & 5 & 4 & 5 & 3 & 5 & 4 & 3 & 5 & 4 \\
\hline & $4(\mathrm{M})$ & 3 & 4 & 3 & 5 & 4 & 5 & 3 & 3 & 5 \\
\hline & Total & 17 & 17 & 15 & 17 & 18 & 17 & 12 & 15 & 18 \\
\hline
\end{tabular}

Similar compiled data for other parameters are given in next section. The membership functions required for computation of performance score for each criterion with respect to alternatives are also developed.

\subsection{The proposed algorithm}

The application of the linguistic fuzzy AHP comprises of the following steps:

Step 1 : Structuring the Problem as a Hierarchy

The problem can be structured into a hierarchy as shown in the Fig 2. On the top level, there is the overall goal i.e. selection of the type of manufacturing process. On the second level, there are the five criteria ( $C 1$ through $C 5)$ that contribute to the goal. On the third level, these five criteria are again decomposed into twenty five sub-criteria and on the bottom ( fourth) level are the two alternative choices of manufacturing type that are evaluated in terms of the sub-criteria of the third level.

\section{Step 2: Construction of Membership Function}

Membership functions are constructed using section dilators as reference for each sub criterion represented in Table 3.

\section{Step 3: Calculation of Performance Score}

With the help of this membership function, the performance score is calculated for each sub criterion. For example, considering the value of manufacturing type 1 (manual) and manufacturing type 2 (RE) under sub-criterion performance,

The value of membership function for manufacturing type $1=(7-5) / 15=0.13,5 \leq \mathrm{t} \leq 20$.

Similarly, for manufacturing type 2, the calculated value is $(17-5) / 15=0.8$ 
Next all the scores are aggregated corresponding to its sub criterion (Table 3 and 4).

\section{Step 4: Normalization of the Score}

The decision matrix is normalized to obtain unique membership functions combined with other criteria to select the best manufacturing type. Here normalization is done by adding individual column elements and then dividing each column element by the sum.

\section{Step 5: Dilation or centralization for each criterion}

To determine the power of dilation or centralization for each criterion the various attributes with power of centralization or dilation is given Table 5. Using the power values from this table and applying it on alternative criterion, a set of values represented by a decision matrix is obtained. For example, for $C 2$, the relative weights are obtained by raising the column elements to power of 1.25 i.e. $(0.5)^{1.25}=0.420448$. In this way a decision matrix is obtained (Table 6) representing scores of all criteria with respect to each alternatives.

\section{Step 6: Decision Making}

To determine the best alternative solution, the max-min principle is applied. First by taking the minimum membership value over all of the criterion for different alternatives and then picking the alternative with maximum value. The ranking of best manufacturing type from Table 6 are found and the minimum value of all alternatives with respect to various criterion in the decision matrix are taken. For the given case study,

Minimum of manufacturing Type 1 (conventional) $=0.0169$

Minimum of manufacturing type 2 (RE based) $=0.4099$

Taking the maximum value between the two alternatives, manufacturing type 2 , i.e. RE type is the best option.

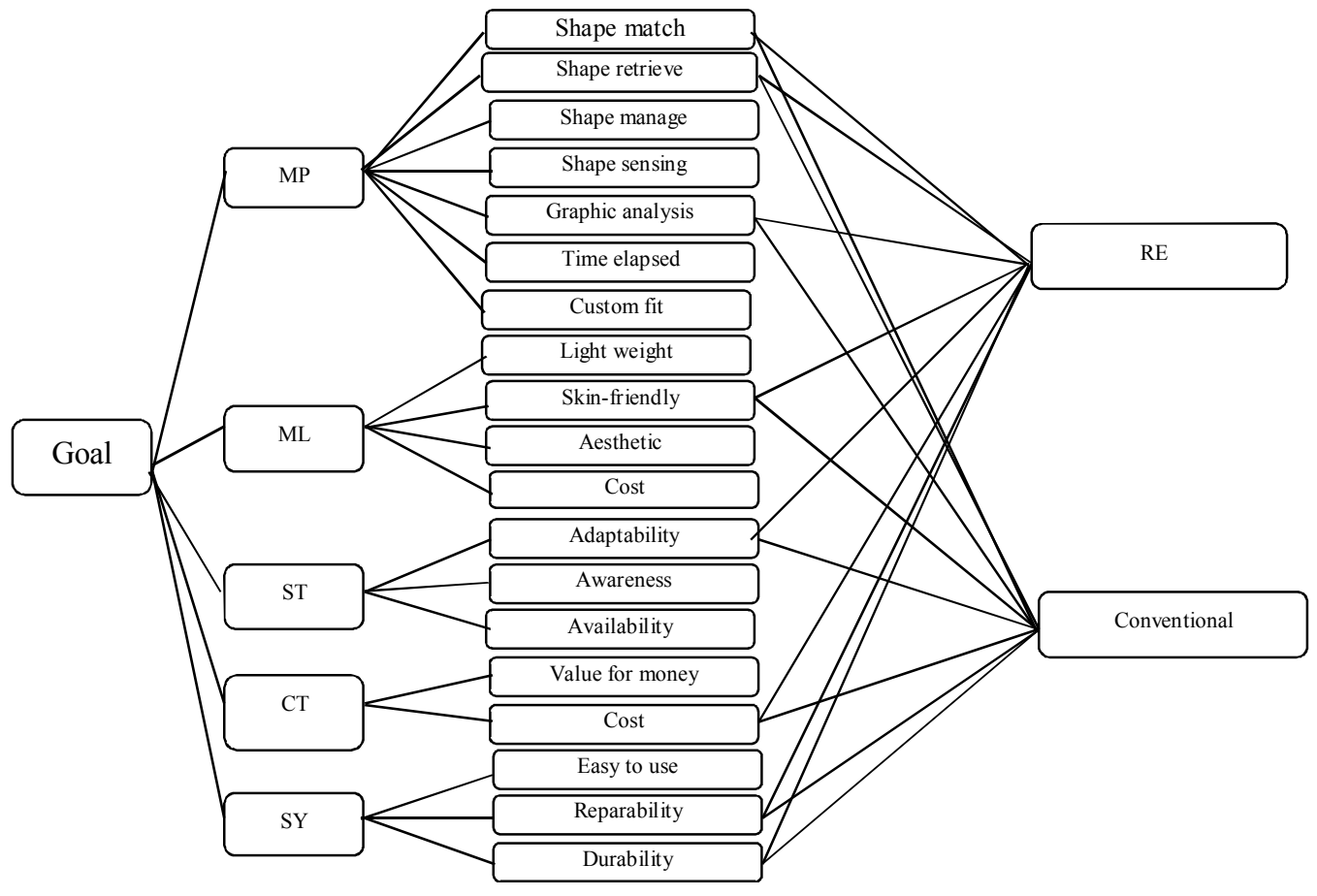

Fig. 2. Hierarchical representation for the selection of manufacturing approach 
Table 3

Membership functions and scores for manufacturing process criteria

\begin{tabular}{|c|c|c|c|c|}
\hline Criteria & Manual & $\mathrm{RE}$ & \multicolumn{2}{|c|}{ Membership Function } \\
\hline Shape matching & $7(0.13)$ & $17(0.8)$ & $\mu_{p}=\left\{\begin{array}{l}(t-5) / 15 \\
1\end{array}\right.$ & $\begin{array}{c}5 \leq t \leq 20 \\
20 \leq t\end{array}$ \\
\hline $\begin{array}{l}\text { Shape } \\
\text { retrieval }\end{array}$ & $6(0.06)$ & $17(0.8)$ & $\mu_{p}=\left\{\begin{array}{l}(t-5) / 15 \\
1,\end{array}\right.$ & $\begin{array}{c}5 \leq t \leq 20 \\
20 \leq t\end{array}$ \\
\hline Shape management & $8(0.17)$ & $15(0.75)$ & $\mu_{p}=\left\{\begin{array}{l}(t-6) / 18 \\
1,\end{array}\right.$ & $\begin{array}{c}6 \leq t \leq 18 \\
18 \leq t\end{array}$ \\
\hline $\begin{array}{l}\text { Biomechanical shape } \\
\text { standard }\end{array}$ & $7(0.08)$ & $17(0.91)$ & $\mu_{p}=\left\{\begin{array}{l}(t-5) / 15 \\
1,\end{array}\right.$ & $\begin{array}{c}5 \leq t \leq 20 \\
20 \leq t\end{array}$ \\
\hline Shape sensing & $7(0.05)$ & $18(0.63)$ & $\mu_{p}=\left\{\begin{array}{l}(t-6) / 19 \\
1,\end{array}\right.$ & $\begin{array}{c}6 \leq t \leq 25 \\
25 \leq t\end{array}$ \\
\hline Graphic analysis & $4(0.05)$ & $17(0.82)$ & $\mu_{p}=\left\{\begin{array}{l}(t-3) / 17 \\
1,\end{array}\right.$ & $\begin{array}{c}3 \leq t \leq 20 \\
20 \leq t\end{array}$ \\
\hline Time elapsed & $6(0.16)$ & $12(0.67)$ & $\mu_{p}=\left\{\begin{array}{l}(t-5) / 15 \\
1,\end{array}\right.$ & $\begin{array}{c}5 \leq t \leq 20 \\
20 \leq t\end{array}$ \\
\hline Custom fit & $9(0.18)$ & $15(0.72)$ & $\mu_{p}=\left\{\begin{array}{l}(t-7) / 15 \\
1,\end{array}\right.$ & $\begin{array}{c}5 \leq t \leq 20 \\
20 \leq t\end{array}$ \\
\hline Further processing & $6(0.13)$ & $18(0.88)$ & $\mu_{p}=\left\{\begin{array}{l}(t-4) / 16 \\
1,\end{array}\right.$ & $\begin{array}{c}4 \leq t \leq 20 \\
20 \leq t\end{array}$ \\
\hline Total & 1.01 & 6.88 & & \\
\hline
\end{tabular}

Table 4

Linguistic data and scores for other parameters

\begin{tabular}{|c|c|c|c|}
\hline & Criteria & Manual & $R E$ \\
\hline \multirow{7}{*}{ Material } & Environment friendly & $11(0.3)$ & $15(0.7)$ \\
\hline & Light weight & $12(0.2)$ & $18(0.8)$ \\
\hline & Easy replaceable & $10(0.72)$ & $11(0.33)$ \\
\hline & Skin friendliness & $11(0.43)$ & $11(0.43)$ \\
\hline & Aesthetic & $12(0.31)$ & $17(0.27)$ \\
\hline & Cost & $18(0.75)$ & $6(0.15)$ \\
\hline & Total & 2.71 & 2.68 \\
\hline \multirow{4}{*}{$\begin{array}{l}\text { Cost } \\
\text { Effectiveness }\end{array}$} & Easy replaceable & $8(0.14)$ & $16(0.71)$ \\
\hline & Skin friendliness & $14(0.11)$ & $18(0.88)$ \\
\hline & Aesthetic & $13(0.15)$ & $16(0.3)$ \\
\hline & Total & 0.4 & 1.89 \\
\hline \multirow{5}{*}{$\begin{array}{l}\text { Smart } \\
\text { Technology }\end{array}$} & Awareness to smart & $5(0.12)$ & $16(0.81)$ \\
\hline & Adaptability & $7(0.13)$ & $16(0.73)$ \\
\hline & Cost & $10(0.13)$ & $12(0.25)$ \\
\hline & Availability & $11(0.15)$ & $18(0.5)$ \\
\hline & Total & 0.53 & 2.29 \\
\hline \multirow{4}{*}{ Serviceability } & Easy-to-use & $13(0.38)$ & $15(0.63)$ \\
\hline & Reparability & $7(0.15)$ & $15(0.77)$ \\
\hline & Durability & $12(0.25)$ & $15(0.63)$ \\
\hline & Total & 0.78 & 2.03 \\
\hline
\end{tabular}

Table 5

Various attributes with power of concentrator or dilators

\begin{tabular}{llc}
\hline Criteria & Hedge & Power \\
\hline$C_{1}:$ Manufacturing process & Very significant & 2 \\
$C_{2}:$ Material & Very important & 1.25 \\
$C_{3}:$ Smart Technology & Somewhat important & 0.33 \\
$C_{4}:$ Cost Effective & More or less important & 0.5 \\
$C_{5}:$ Serviceability & Negatively important & 0.75 \\
\hline
\end{tabular}


Table 6

Final selection of best manufacturing process using max-min principle

\begin{tabular}{rccccc}
\hline & \multicolumn{7}{c}{ Normalized Decision Matrix } \\
\hline & $\mathrm{C} 1$ & $\mathrm{C} 2$ & $\mathrm{C} 3$ & $\mathrm{C} 4$ & $\mathrm{C} 5$ \\
\hline Conventional & 1.01 & 2.71 & 0.53 & 0.4 & 0.78 \\
$\mathrm{RE}$ & 6.88 & 2.68 & 2.29 & 1.89 & 2.03 \\
\hline \multicolumn{7}{c}{ Concentrated/Dilated } \\
\hline Conventional & 0.13 & 0.5 & 0.2 & 0.17 & 0.28 \\
$\mathrm{RE}$ & 0.87 & 0.49 & 0.81 & 0.82 & 0.72 \\
\hline \multicolumn{7}{c}{ Decision Matrix } \\
\hline Conventional & 0.0169 & 0.420448 & 0.587949 & 0.412311 & 0.384918 \\
$\mathrm{RE}$ & 0.7569 & 0.409963 & 0.932825 & 0.905539 & 0.781627 \\
\hline
\end{tabular}

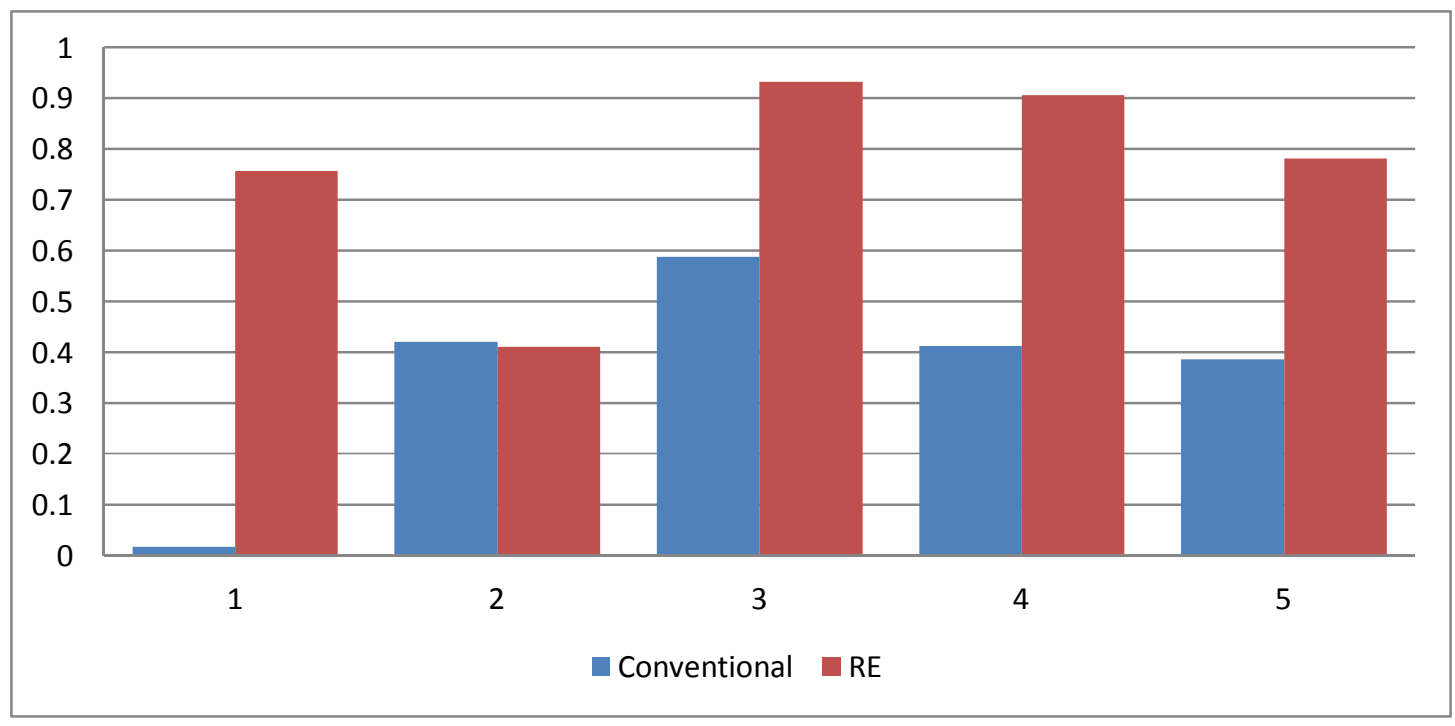

Fig 3. Selection of best alternative using max-min principle

In Fig. 3 a graphical depiction of relative weights from the decision matrix is produced to clearly select the maximum value for the RE-based manufacturing approach which can be selected in order to achieve the manufacturing excellence leading user satisfaction.

\section{Conclusions}

In this paper, a fuzzy linguistic hedges based AHP tool is implemented to analyse the responses from the users of the prosthetic sockets manufactured conventionally as well as using RE based approach. Four manufacturing units dealing with prosthetic sockets were taken for the study and users were identified for getting the responses on both the approaches of manufacturing. Five design parameters along with their rankings as obtained from a fuzzy QFD analysis earlier by the authors were used in the present work. A hierarchical problem is constructed to select the best alternative of manufacturing using the max-min principle of the linguistic hedges. Decision matrices are formed after normalization and using concentrators/dilators to the scoring weights. From the decision matrix the RE-based approach was selected as a better alternative which can satisfy the user requirements and achieve the manufacturing excellence. In present times the SMEs are enhancing their capabilities by procuring advanced technologies. During the survey, many rehabilitation units were found, those in the process of acquiring the RE-based technology to replace the manual or conventional method. 


\section{References}

Aktepe, A., \& ERSOZ, S. (2011). A fuzzy analytic hierarchy process model for supplier selection and a case study. International Journal of Research and Development, 3(1), 33-37.

Daim, T., Udbye, A., \& Balasubramanian, A. (2012). Use of analytic hierarchy process (AHP) for selection of 3PL providers. Journal of Manufacturing Technology Management, 24(1), 3-3.

Dangayach, G. S., \& Deshmukh, S. G. (2005). Advanced manufacturing technology implementation: evidence from Indian small and medium enterprises (SMEs). Journal of Manufacturing Technology Management, 16(5), 483-496.

Foort, J., Spiers, R., \& Bannon, M. (1985). Experimental fittings of sockets for below-knee amputees using computer aided design and manufacturing techniques. Prosthetics and Orthotics International, 9(1), 46-47.

Holden, J. M., \& Fernie, G. R. (1986). Results of the pilot phase of a clinical evaluation of computer aided design of trans-tibial prosthesis sockets. Prosthetics and Orthotics International, 10(3), 142148.

Klasson, B. (1985). Computer aided design, computer aided manufacture and other computer aids in prosthetics and orthotics. Prosthetics and Orthotics International, 9(1), 3-11.

Kwong, C. K., \& Bai, H. (2002). A fuzzy AHP approach to the determination of importance weights of customer requirements in quality function deployment. Journal of intelligent manufacturing, 13(5), 367-377.

Lascio, L. D., Gisolfi, A., \& Loia, V. (1996). A new model for linguistic modifiers. International Journal of Approximate Reasoning, 15(1), 25-47.

Le, T. P. N., Genovese, A., \& Koh, L. S. (2011). Using FAHP to determine the criteria for partner's selection within a green supply chain: the case of hand tool industry in Taiwan. Journal of Manufacturing Technology Management, 23(1), 25-55.

Nepal, B., Natarajarathinam, M., \& Balla, K. (2011). Improving manufacturing process for biomedical products: a case study. Journal of Manufacturing Technology Management, 22(4), 527-540.

Ho, N. C., \& Nam, H. V. (2002). An algebraic approach to linguistic hedges in Zadeh's fuzzy logic. Fuzzy Sets and Systems, 129(2), 229-254.

Ho, N. C., \& Wechler, W. (1992). Extended hedge algebras and their application to fuzzy logic. Fuzzy sets and systems, 52(3), 259-281.

Bayazit, O. (2005). Use of AHP in decision-making for flexible manufacturing systems. Journal of Manufacturing Technology Management, 16(7), 808-819.

Zadeh, L. A. (1965). Fuzzy sets. Information and control, 8(3), 338-353.

Zadeh, L. A. (1972). A fuzzy-set-theoretic interpretation of linguistic hedges.

Zadeh, L. A. (1975). The concept of a linguistic variable and its application to approximate reasoning-I. Information sciences, 8(3), 199-249. 